\title{
Left bundle branch block as equivalent of ST-segment elevation myocardial infarction: when yes, when not?
}

\author{
Bloqueo de rama izquierda como equivalente ST, ¿cuándo sí, cuándo no? \\ Laura Ceballos-Naranjo ${ }^{1}$ and Jonathan Cardona-Vélez ${ }^{2 *}$ \\ ${ }^{1}$ Faculty of Medicine, Universidad Pontificia Bolivariana; ${ }^{2}$ Internal Medicine, Universidad de Antioquia, Hospital Universitario San Vicente Fundación. \\ Medellín, Colombia
}

\begin{abstract}
A new or presumably new left bundle branch block along with ischemic symptoms has traditionally been considered an electrocardiographic equivalent of ST-segment elevation myocardial infarction, which should be brought to emergent reperfusion. However, several criteria have been proposed for its definition, but none has reached out an optimal diagnostic yield. Below we detail these criteria, their main problems and the advantages they have shown.
\end{abstract}

Key words: Electrocardiography. ST elevation myocardial infarction. Left bundle branch block. Internal medicine. Cardiology. Colombia.

\section{Resumen}

La presencia de un bloqueo de rama izquierda del haz de His nuevo o presumiblemente nuevo junto con síntomas isquémicos se ha considerado tradicionalmente un equivalente electrocardiográfico de infarto agudo de miocardio con elevación del segmento ST, el cual debe ser llevado a reperfusión emergente. Para su definición se han propuesto varios criterios, pero ninguno ha alcanzado un rendimiento diagnóstico óptimo. A continuación detallaremos dichos criterios, sus principales problemas y las ventajas que han demostrado.

Palabras clave: Electrocardiografía. Infarto agudo de miocardio con elevación del segmento ST. Bloqueo de rama izquierda. Medicina interna. Cardiología. Colombia.

\section{Correspondence:}

*Jonathan Cardona-Velez

E-mail: jcardonavelez@ hotmail.com
Date of reception: 23-01-2018

Date of acceptance: 08-08-2018

DOI: 10.24875/ACME.M19000004
Available online: 09-08-2019 Arch Cardiol Mex (Eng). 2019;89(1):20-25

www.archivoscardiologia.com 2604-7063 @ 2018 Instituto Nacional de Cardiología Ignacio Chávez. Published by Permanyer México. This is an open access article under the CC BY-NC-ND license (http://creativecommons.org/licenses/by-nc-nd/4.0/). 


\section{Introduction}

Electrocardiogram (ECG) is a determining tool in the assessment of patients with chest pain, since it allows establishing the diagnosis of acute myocardial infarction (AMI), especially in those with ST-segment elevation (STEMI); however, in the presence of left bundle branch block (LBBB), repolarization abnormalities modify the morphology of waves and difficult their reading'.

In view of these considerations, several criteria have been proposed to facilitate AMI diagnosis in the presence of LBBB, but none has reached optimal diagnostic performance ${ }^{2}$. Sgarbossa, et al. were the first to propose an electrocardiographic score for the diagnosis of $\mathrm{AMI}$ in the presence of this entity ${ }^{3}$; however, although it has high specificity, sensitivity is still very low. Subsequently, Smith, et al. proposed a modification to these criteria that, according to their results, significantly increase sensitivity ${ }^{4}$.

\section{Left bundle branch block as ST equivalent?}

In the context of this diagnostic uncertainty, the presence of a new or presumably new LBBB together with ischemic symptoms has been traditionally considered an electrocardiographic equivalent to STEMI, which must be brought to urgent reperfusion'; however, recent studies have shown a low incidence of AMI in patients with $\mathrm{LBBB}^{5,6}$. Owing to these findings, treatment guidelines radically changed after 20 years.

The 1996 and 2004 American Heart Association (AHA) guidelines 7,8 recommended immediate reperfusion therapy in patients with a new or presumably new LBBB who had ischemic symptoms, based on a meta-analysis that showed that fibrinolysis was associated with a survival increase in patients with LBBB and $\mathrm{AMI}^{\text {; }}$; however, this recommendation was abolished in the 2013 guidelines ${ }^{10}$. This change reduces the incidence of unnecessary fibrinolytic therapy that may cause hemorrhages, mainly in high-risk population, although not performing adequate reperfusion therapy in patients with a true coronary artery occlusion can increase morbidity and mortality in this population'.

In 2012, the European Society of Cardiology (ESC) STEMI guidelines, and in 2014, the European Society of Cardiothoracic Surgery myocardial revascularization guidelines, recommended the performance of percutaneous coronary intervention (PCl) or pharmacological reperfusion for patients with ischemic symptoms showing a new or presumably new LBBB in the ECG ${ }^{11,12}$. In 2017, the latest ESC STEMI guidelines were published, where they do not only continue making the same recommendation, but they also suggest the use of the Sgarbossa criteria, emphasizing that concordant ST-segment elevation is one of the best indicators of $\mathrm{AMI}^{13}$.

In 1996, Sgarbossa et al. published their criteria based on a sub-analysis of the GUSTO trial $^{3}$, where

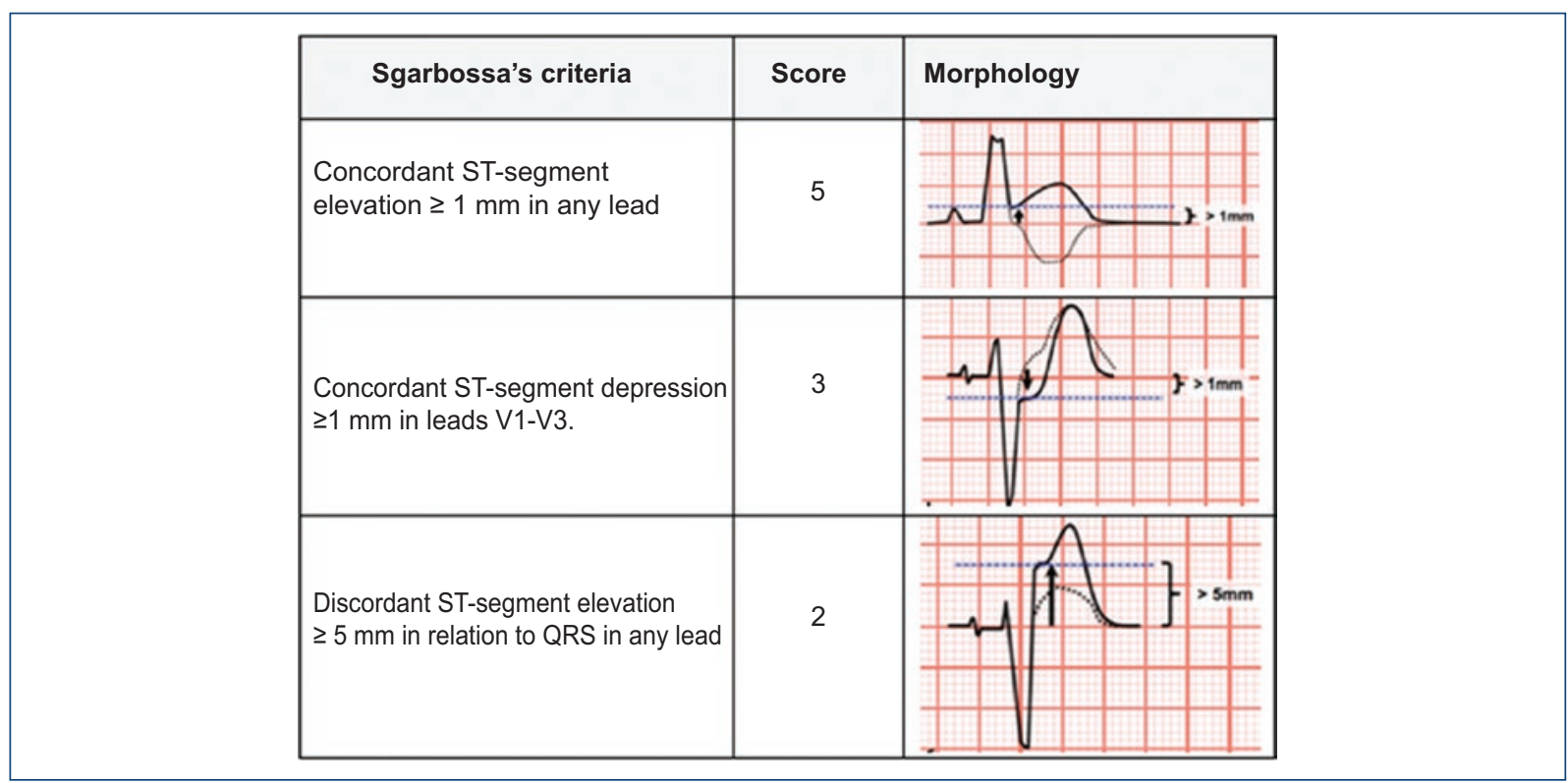

Figure 1. Sgarbossa's criteria for STEMI diagnosis in the presence of LBBB. A score lower than 3 is not traditionally considered diagnostic for STEMI, but does not rule it out. 


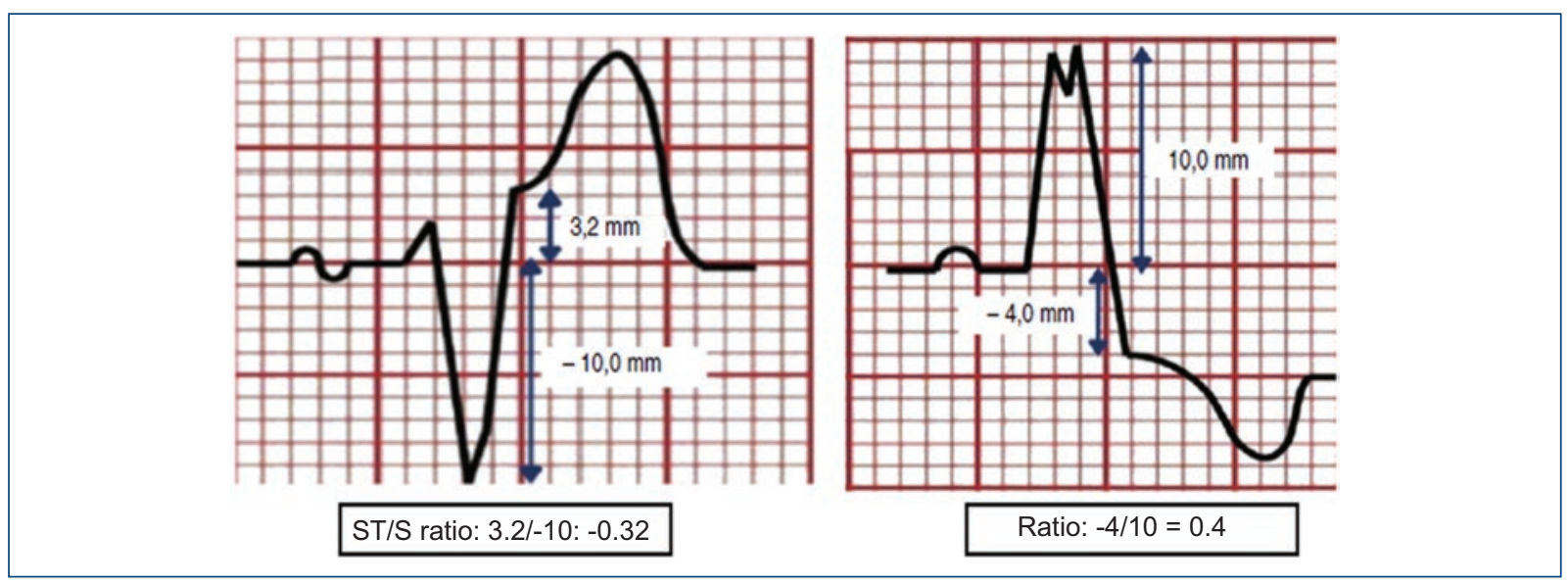

Figure 2. Electrocardiographic proportionality criterion: ST/S ratio calculation (adapted from Cai et al., 2013) ${ }^{23}$.

Table 1. Smith rules for STEMI diagnosis in the presence of LBBB

\begin{tabular}{|l|l|}
\hline Smith Rules & Description \\
\hline Smith's rule I: Sgarbossa score $\geq 3$ & ST concordant elevation $\geq 1 \mathrm{~mm}$ or ST concordant depression $\geq 1 \mathrm{~mm}$ in leads V1-V3 \\
\hline Smith's rule II: Sgarbossa score $\geq 2$ & Sgarbossa score $\geq 3$ or ST discordant elevation $\geq 5 \mathrm{~mm}$ \\
\hline Smith's rule III & Sgarbossa score $\geq 3$ or ST discordant elevation with an ST/S ratio $\leq-0.25$ \\
\hline Smith's rule IV & Sgarbossa score $\geq 3$ or ST discordant elevation with an ST/S ratio $\leq-0.3$ \\
\hline Smith's rule V & ST discordant deviation with a ST/S or ST/R ratio $\leq-0.3$ \\
\hline
\end{tabular}

$0.6 \%$ of patients with AMI had LBBB. Sgarbossa's criteria (Fig. 1) are based on a scoring system where three or more points are required for AMI diagnosis in the presence of LBBB, typically known as weighted criteria. Criteria without this scoring system can be also used and, in this case, any of the three criteria is accepted, a modality known as unweighted, which is more sensitive but less specific ${ }^{4,14}$.

These criteria largely contributed to solve multiple problems when facing an ECG with LBBB in patients with ischemic symptoms; however, the study had two important limitations, ${ }^{1,4}$ and thus it is not surprising that the attempts to validate the electrocardiographic criteria have shown a useful specificity but poor sensitivity:

- The study used creatine kinase MB (CK-MB) elevation as AMl outcome instead of using acute coronary occlusion angiographic evidence, which limits the sensitivity of the rule, since it combines STEMI and non-ST AMI in the definition of its outcome.

- Sgarbossa, et al. used an absolute limit of $5 \mathrm{~mm}$ for ST-segment discordant elevation, instead of a proportional criterion relating it to the QRS or $S$ voltage that precedes it, which could be more useful in terms of sensitivity and specificity ${ }^{1,3,4}$.

Although Sgarbossa's criteria are an important advance, they have the limitation of their low sensitivity. In a meta-analysis, a general sensitivity of $20 \%$ and specificity of $96 \%$ were observed, for a Sgarbossa score higher than or equal to three ${ }^{14,15}$. However, the combination of the first two criteria (ST-segment concordant elevation in any lead and ST-segment concordant depression in V1-V3), contributes to sensitivity and specificity increase by 37.2 and $96.6 \%$, respectively ${ }^{16}$. Similar findings have been encountered in multiple studies where ST-segment concordant elevation or depression have been shown to be an independent AMI predictor ${ }^{17}$, and ST-segment concordant elevation has been shown to be the most specific individual criterion for the diagnosis of $\mathrm{AMI}$ in the presence of $\mathrm{LBBB}^{18}$.

Approximately nine years after the emblematic study by Sgarbossa et al., a report by the Hirulog and early reperfusion or occlusion trial (HERO-2) researchers compared the three Sgarbossa criteria and analyzed their 30-day prognostic value. In the original HERO-2 


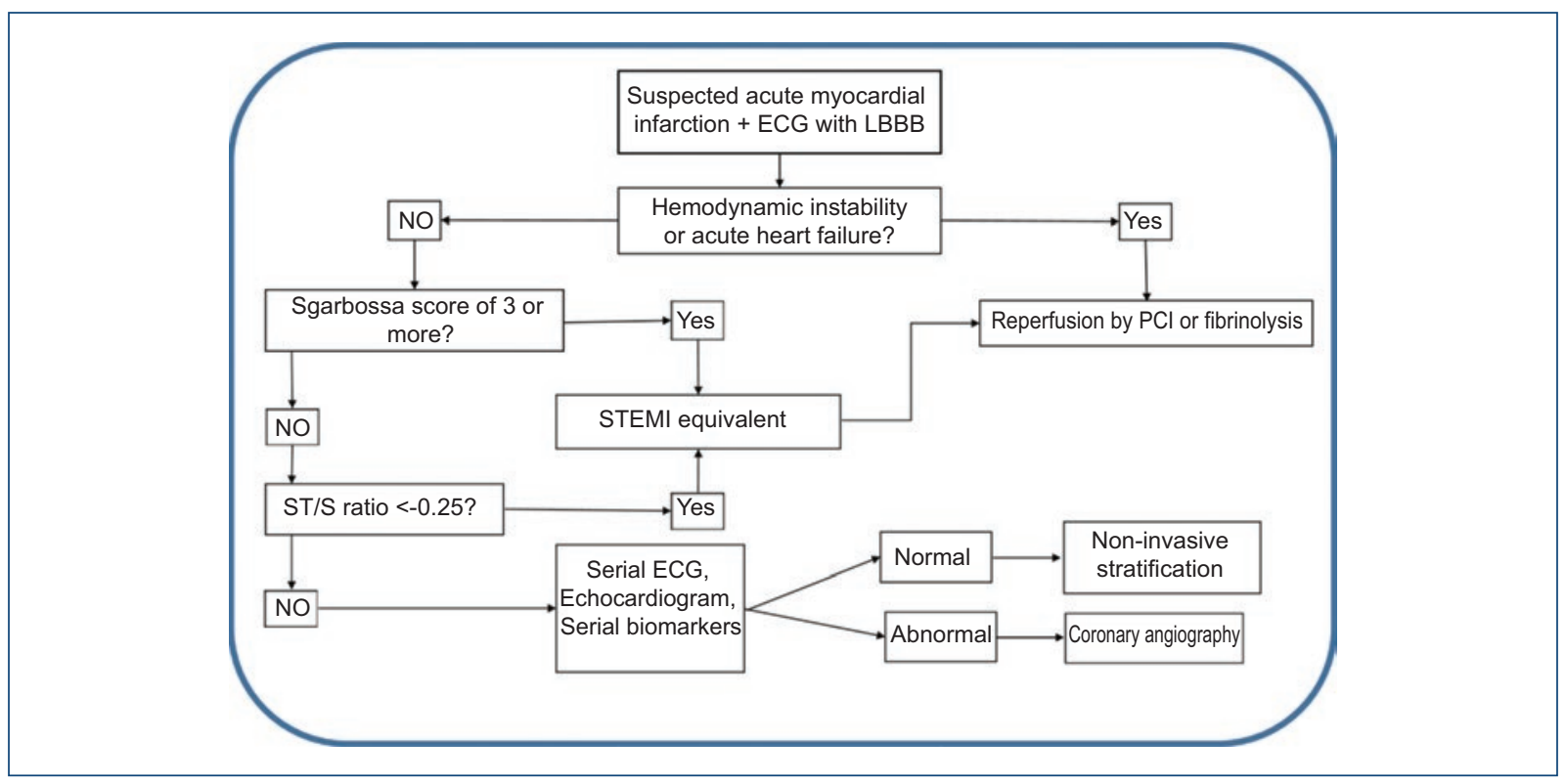

Figura 3. Simplified algorithm for the diagnosis of STEMI in the presence of LBBB (adapted from Cai et al., 2013) ${ }^{23}$. PCI: Percutaneous coronary intervention.

study, 300 patients had ischemic symptoms (more than 30 minutes with angina) and new or presumably new LBBB; these subjects were compared with a control group of 300 patients with no LBBB in the ECG. Of the 300 patients with LBBB, 92 met the criteria established by Sgarbossa et al. ${ }^{19}$.

AMI, as determined by creatine kinase levels, occurred in $80.7 \%$ of patients with LBBB and in $88.7 \%$ of controls $(p=0.006)$. ST-segment changes were specific but not sensitive for AMI diagnosis. In addition, mortality was higher in patients with LBBB. The study confirmed the following ${ }^{19}$ :

1. ST-segment concordant elevation of more than $1 \mathrm{~mm}$ in any lead has high specificity (98.3\%) but low sensitivity $(33.5 \%)$ for AMI.

2.ST-segment concordant depression of more of $1 \mathrm{~mm}$ in V1 to V3 leads has high specificity; however, sensitivity was also very low (14.1\%).

3.ST-segment discordant elevation of more of $5 \mathrm{~mm}$ was neither sensitive $(29.3 \%)$ nor specific $(58.6 \%)$ for AMI diagnosis.

The low usefulness of Sgarbossa's third criterion (discordant elevation higher than $5 \mathrm{~mm}$ in relation to QRS in any lead) is because the relationship between ST-segment elevation and the QRS voltage that precedes it (ST/S ratio) is not considered, a concept known as proportionality ${ }^{14}$; this corresponds to the ratio obtained between the ST-segment discordant elevation amplitude measured from point $\mathrm{J}$ in precordial leads ${ }^{4}$ and anterior QRS amplitude (Fig. 2) $)^{1,20}$. In other words, this rule is based on the fact that repolarization is proportional to depolarization, an essential concept for STEMI diagnosis in the scenario of morphological abnormalities present in branch blocks or ventricular hypertrophies ${ }^{1,21 .}$

Smith et al. were the first to assess Sgarbossa's algorithms using $\mathrm{PCl}$ in the definition of their outcome, ${ }^{4,22}$ and in an attempt to improve sensitivity, they replaced the third criterion with a statistical relationship. In this case-control study, where patients with LBBB and acute coronary occlusion were analyzed, implementation of both concordance criteria together with an ST/S ratio $\leq-0.25$ had better results, with a sensitivity of $91 \%$, specificity of $90 \%$ and LR+ 9, LR- $0.14,14,16$.

Smith's rules I and II correspond to Sgarbossa's criteria with and without the scoring system, respectively; with a score of three or more for rule I and two or more for rule II being necessary for STEMI diagnosis. Rule III represents a modification of rule II, where the use of an absolute measurement is replaced by a relative discordance measurement. Rule IV consists in making a relative measurement of discordant deviation, either ST-segment elevation or depression, instead of ST-segment elevation absolute discordance. Finally, rule $\mathrm{V}$ is based on proportional discordance, either by ST-segment elevation or depression (Table 1$)^{4}$.

In a study carried out by Meyers HP et al., Smith's rules were found to be significantly more sensitive than Sgarbossa's criteria ${ }^{1}$. Di Marco A et al. had similar results; 145 patients were included in their study, out of 
whom 37 had a clinical presentation consistent with STEMI. They demonstrated that Smith's rules III and IV showed better results than Sgarbossa's criteria and had good specificity, of 90 and $97 \%$ respectively; however, sensitivity was $67 \%$ for Smith's rule III and $54 \%$ for rule IV, which is still suboptimal ${ }^{22}$.

Even though Smith's rules significantly improved sensitivity with respect to Sgarbossa's criteria for the diagnosis of STEMI in the presence of LBBB, they have a significant limitation related to the difficulty of implementation in clinical practice. Cai et al. proposed a simplified diagnostic algorithm that facilitates its systematic use, which includes the implementation of additional diagnostic aids that favor the approach to this type of patients (Fig. 3$)^{23}$.

\section{Conclusion}

Electrocardiographic definition of STEMI in the presence of LBBB continues to be a challenge despite multiple attempts to accurately characterize this condition. Thus, it is no surprise that great international scientific societies provide different recommendations. The last 2017 ESC guidelines for the treatment of STEMI are the only ones so far in recommending the use of electrocardiographic criteria to facilitate the diagnosis of AMI in the presence of LBBB and in considering it as an ST equivalent; however, why do they recommend the use of Sgarbossa's criteria when Smith's rules have been shown to be more sensitive and specific?

The answer could be associated with the ease in their application versus Smith's rules, which despite being promising, still have poor sensitivity.

There are still many questions to be answered, which makes for appropriate treatment of patients with suspected AMI in the presence of LBB to remain controversial and challenging, which is why there is the need to continue in the search for electrocardiographic criteria that enable identifying those patients who really need urgent reperfusion and avoiding the performance of procedures that might generate more morbidity and mortality. In addition, the use of tools complementary to ECG, such as echocardiogram and biomarkers, can provide useful information in diagnostic and therapeutic dilemmas.

\section{Conflicts of interest}

The authors declare not having any conflicts of interest or having received funding.

\section{Ethical disclosures}

Protection of people and animals. The authors declare that no experiments have been conducted on humans or animals for this research.

Confidentiality of data. The authors declare having followed the protocols of their work center on the publication of patient data.

Right to privacy and informed consent. The authors declare that no patient data appear in this article.

\section{References}

1. Meyers HP, Limkakeng AT Jr, Jaffa EJ, Patel A, Theiling BJ, Rezaie SR, et al. Validation of the modified Sgarbossa criteria for acute coronary occlusion in the setting of left bundle branch block: A retrospective case-control study. Am Heart J. 2015;170(6):1255-64.

2. Ciliberti G, Del Pinto M, Notaristefano F, Zingarini G, Ambrosio G, Cavallini $C$. Left bundle branch block, chest pain and catheterization laboratory activation: an unavoidable cascade reaction? J Electrocardiol. 2016;49(4):504-8.

3. Sgarbossa EB, Pinski SL, Barbagelata A, Underwood DA, Gates KB, Topol EJ, et al. Electrocardiographic diagnosis of evolving acute myocardial infarction in the presence of left bundle-branch block. GUSTO-1 (Global Utilization of Streptokinase and Tissue Plasminogen Activator for Occluded Coronary Arteries) Investigators. N Engl J Med. 1996;334:481-7.

4. Smith SW, Dodd KW, Henry TD, Dvorak DM, Pearce LA. Diagnosis of ST-elevation myocardial infarction in the presence of left bundle branch block with the ST-elevation to S-wave ratio in a modified Sgarbossa rule. Ann Emerg Med. 2012;60:766-76.

5. Becker S, Chisholm G, Maeng M. Positive predictive value of clinically suspected ST-segment elevation myocardial infarction using angiographic verification. Am J Cardiol. 2013;112:923-7.

6. Neeland I, Kontos M, Lemos J. Evolving considerations in the management of patients with left bundle branch block and suspected myocardial infarction. J Am Coll Cardiol. 2012;60:96-105.

7. Ryan TJ, Anderson JL, Antman EM, Braniff BA, Brooks NH, Califf RM, et al. ACC/AHA guidelines for the management of patients with acute myocardial infarction. A report of the American College of Cardiology/ American Heart Association Task Force on Practice Guidelines (Committee on Management of Acute Myocardial Infarction). J Am Coll Cardiol. 1996;28(5):1328-428.

8. Antman EM, Anbe DT, Armstrong PW, Bates ER, Green LA, Hand M, et al. ACC/AHA guidelines for the management of patients with ST-elevation myocardial infarction: a report of the American College of Cardiology/American Heart Association Task Force on Practice Guidelines (Committee to Revise the 1999 Guidelines for the Management of Patients with Acute Myocardial Infarction). J Am Coll Cardiol. 2004; 44(3):E1-211.

9. Indications for fibrinolytic therapy in suspected acute myocardial infarction: Collaborative overview of early mortality and major morbidity results from all randomised trials of more than 1000 patients. Fibrinolytic Therapy Trialists' (FTT) Collaborative Group. Lancet. 1994;343(8893):311-22.

10. Anderson JL, Adams CD, Antman EM, Bridges CR, Califf RM, Casey DE Jr, et al. 2012 ACCF/AHA focused update incorporated into the ACCF/AHA 2007 guidelines for the management of patients with unstable angina/ non-ST-elevation myocardial infarction: A report of the American College of Cardiology Foundation/American Heart Association Task Force on Practice Guidelines. J Am Coll Cardiol. 2013;61(23):e179-347.

11. Task Force on the management of ST-segment elevation acute myocardial infarction of the European Society of Cardiology (ESC), Steg PG, James SK, Atar D, Badano LP, Blömstrom-Lundqvist C, Borger MA, et al. ESC Guidelines for the management of acute myocardial infarction in patients presenting with ST-segment elevation. Eur Heart J. 2012; 33(20):2569-619.

12. Authors/Task Force members, Windecker S, Kolh P, Alfonso F, Collet JP, Cremer J, Falk V, et al. 2014 ESC/EACTS Guidelines on myocardial revascularization: The Task Force on Myocardial Revascularization of the European Society of Cardiology (ESC) and the European Association for Cardio-Thoracic Surgery (EACTS). Developed with the special contribution of the European Association of Percutaneous Cardiovascular Interventions (EAPCI). Eur Heart J. 2014;35(37):2541-619.

13. Ibanez B, James S, Agewall S, Antunes MJ, Bucciarelli-Ducci C, Bueno H, et al. ESC Scientific Document Group. 2017 ESC Guidelines for the 
management of acute myocardial infarction in patients presenting with ST-segment elevation: The Task Force for the management of acute myocardial infarction in patients presenting with ST-segment elevation of the European Society of Cardiology (ESC). Eur Heart J. 2018;39(2):119-77.

14. Herweg B, Marcus MB, Barold SS. Diagnosis of myocardial infarction and ischemia in the setting of bundle branch block and cardiac pacing. Herzschrittmacherther Elektrophysiol. 2016;27(3):307-22.

15. Tabas JA, Rodriguez RM, Seligman HK, Goldschlager NF. Electrocardiographic criteria for detecting acute myocardial infarction in patients with left bundle branch block: A meta-analysis. Ann Emerg Med. 2008;52(4):329-36.e1.

16. Moreno NL. Criterios de Sgarbossa: ¿es momento de actualizarlos? Rev Col Cardiol. 2015;22(6):294-7.

17. Kontos MC, Aziz HA, Chau VQ, Roberts CS, Ornato JP, Vetrovec GW. Outcomes in patients with chronicity of left bundle-branch block with possible acute myocardial infarction. Am Heart J. 2011;161(4):698-704.

18. Jain S, Ting HT, Bell M, Bjerke CM, Lennon RJ, Gersh BJ, et al. Utility of left bundle branch block as a diagnostic criterion for acute myocardial infarction. Am J Cardiol. 2011;107(8):1111-6.

19. Wong CK, Stewart RA, Gao W, French JK, Raffel C, White HD. Prognostic differences between different types of bundle branch block during the early phase of acute myocardial infarction: insights from the Hirulog and Early Reperfusion or Occlusion (HERO)-2 trial. Eur Heart J. 2006; 27(1):21-8.

20. Pera VK, Larson DM, Sharkey SW, Garberich RF, Solie CJ, Wang YL, et al. New or presumed new left bundle branch block in patients with suspected ST-elevation myocardial infarction. Eur Heart J Acute Cardiovasc Care. 2018;7(3):208-17.

21. Armstrong EJ, Kulkarni AR, Bhave PD, Hoffmayer KS, Macgregor JS, Stein JC, et al. Electrocardiographic criteria for ST-elevation myocardial infarction in patients with left ventricular hypertrophy. Am J Cardiol. 2012;110(7):977-83.

22. Di Marco A, Anguera I, Rodríguez M, Sionis A, Bayes-Genis A, Rodríguez $\mathrm{J}$, et al. Evaluación de los algoritmos de Smith para el diagnóstico de infarto agudo de miocardio en presencia de bloqueo de rama izquierda del haz de His. Rev Esp Cardiol. 2017;70(7):559-66.

23. Cai Q, Mehta N, Sgarbossa EB, Pinski S, Wagner G, Califf R, et al. The left bundle-branch block puzzle in the 2013 ST-elevation myocardial infarction guideline: From falsely declaring emergency to denying reperfusion in a high-risk population. Are the Sgarbossa criteria ready for prime time? Am Heart J. 2013;166(3):409-13. 